Personalidade Acadêmica Homenageada:

Carlos Aurélio Mota de Souza (Universidade Ibirapuera - UNIB)

\title{
AS NOVAS RELAÇÕES DE TRABALHO, PRECARIZAÇÃO E A DIGNIDADE DO TRABALHADOR NO MODELO UBER
}

\section{THE NEW RELATIONSHIPS OF LABOR, PRECARISATION AND THE DIGNITY OF THE WORKER IN THE MODEL UBER}

\section{BRUNO ROBERTO VOSGERAU}

Mestrando do Programa Direito Empresarial e Cidadania (Centro Universitário Curitiba - UniCuritiba) (2017). Especializado em direito do trabalho e processual do trabalho pela Pontifícia Universidade Católica do Paraná (2015). Especializado em direito público pelo Centro universitário Maringá (UniCesumar) (2015). Graduado em Direito pela Universidade Católica de Brasília (2011). Experiência com contencioso de massa, contratos e relação de consumo. Experiência em direito tributário e administrativo.

RODRIGO THOMAZINHO COMAR Mestrando em Direito Empresarial, Cidadania e Efetividade pela Unicuritiba. Possui pós-graduação em Direito e Processo Civil pela Pontifícia Universidade Católica do Paraná.

\section{RESUMO}

Trata o presente artigo da análise da prestação de serviços realizada pelo motorista mediante a intermediação feita pelo aplicativo UBER, tendo em vista a inovação apresentada em relação ao fator econômico e seus efeitos perante a estrutura clássica. O estudo também aborda o tema pelo viés trabalhista, seus efeitos em relação a natureza jurídica da relação, bem como o enfoque da Justiça do Trabalho no tocante a tal situação. No mesmo sentido, será abordada a questão acerca dos 


\section{Personalidade Acadêmica Homenageada:}

\section{Carlos Aurélio Mota de Souza (Universidade Ibirapuera - UNIB)}

elementos que permitem concluir se o trabalho prestado respeita os direitos da personalidade do trabalhador, tais como o da dignidade da pessoa humana, bem como se tal situação esta em conformidade com a agenda do trabalho decente estabelecida pela Organização Internacional do Trabalho e se resulta em precarização das condições de trabalho.

PALAVRAS-CHAVE: UBER; Trabalho decente; Precarização; Novas relações de trabalho.

\section{ABSTRACT}

It deals with the present article of the analysis of the service rendered by the driver through the intermediary made by the UBER application, considering the innovation presented in relation to the economic factor and its effects before the classic structure. The study also addresses the issue of labor bias, its effects in relation to the legal nature of the relationship, as well as the Labor Justice approach to this situation. In the same vein, the question will be addressed as to whether the work performed respects the rights of the employee's personality, such as the dignity of the human person, and whether this is in accordance with the established decent work agenda by the International Labor Organization and results in precarious working conditions.

KEYWORDS: UBER; Decent work; Precariousness; New working relationships.

\section{INTRODUÇÃO}

O desenvolvimento de novas tecnologias tem modificado as relações sociais, em especial as relativas ao trabalho. Há uma modificação nas estruturas clássicas, uma vez que muitas empresas não possuem mais estruturas físicas, sendo apenas uma entidade virtual com a qual os trabalhadores se relacionam, a exemplo da empresa UBER. 


\section{Personalidade Acadêmica Homenageada:}

\section{Carlos Aurélio Mota de Souza (Universidade Ibirapuera - UNIB)}

Em virtude de sua notoriedade no cenário nacional, e até mesmo internacional, o presente trabalho propõem analisar as características de seu modelo de atividade, notadamente quanto a forma da relação de trabalho existente entre a empresa e os chamados de "parceiros" e a sua relação com o trabalho precário e a dignidade do trabalhador.

Nesta inovadora forma de desenvolvimento de atividade econômica, a empresa não possui os instrumentos para prestação do serviço, uma vez que não detém uma frota de veículos nem motoristas empregados, neste ponto surge o primeiro questionamento, seria a empresa UBER caracterizada como empregadora? Ou sua relação com os motoristas seria pautada em um contrato comercial de prestação de serviços, de modo que o aplicativo apenas seria um instrumento de conexão entre quem quer prestar um serviço e quem quer contratá-lo?

Para a obtenção da resposta verificou-se as características deste modelo de atividade, os requisitos necessários à configuração do vínculo empregatício bem como o posicionamento da jurisprudência, que até o momento demonstra-se conflitante.

O segundo ponto o que se buscou esclarecer é relativo ao impacto e do direito social ao trabalho nos direitos da dignidade da pessoa humana e da personalidade do trabalhador.

Para obter subsídios suficiente a uma resposta, analisou-se o princípio da dignidade humana e o direito social do trabalho na sua aptidão em fornecer o chamado "mínimo necessário" para uma vida digna, nele, compreendidas todas as necessidades básicas do ser humano para que sua existência seja digna.

Nesse sentido, como direito social do trabalho deve conduzir à proteção daquele grupo de indivíduos que na sociedade ocupam uma posição social desfavorecida, cabe ao Estado regulamentar e normatizar relações econômicas com vistas a promoção social.

O direito ao trabalho sempre deverá observar condições mínimas para que a dignidade daquele que o exerce seja respeitada.

Em que pese tal necessidade, nota-se que a tendência atual é contrária, uma vez que o surgimento cada vez maior de trabalhos precários e a flexibilização da proteção dada ao trabalhador pelo Estado conduzem à uma ideia de licitude e até 


\section{Personalidade Acadêmica Homenageada:}

Carlos Aurélio Mota de Souza (Universidade Ibirapuera - UNIB)

mesmo de estimulo do exercício de atividades cada vez menos dignas a uma vida saudável, seja pelo modo como são exercidas, seja pela forma como são remuneradas.

Assim, a dignidade da pessoa humana é respeitada quando o trabalho permite ao indivíduo obter o mínimo necessário a uma vida digna.

Ainda, o presente trabalho buscou a definição de trabalho decente, elemento capaz de concretizar o princípio da dignidade da pessoa humana e também atender ou garantir um patamar mínimo civilizatório em tal ambiente, posto que o direito do trabalho conserva, como um de seus objetivos, uma função de civilidade, além de se garantir o atendimento ao princípio da vedação ao retrocesso, além de buscar evitar a precarização da relação entre capital e trabalho.

Isso porque o fato de que sem as condições mínimas de prestação de trabalho decente, o trabalhador estará inserido em uma relação de precarização, o que só torna mais grave a situação de retrocesso social e, por conseguinte, a referida prestação de serviços não atende a fundamentos da Constituição da República, tais como a dignidade da pessoa humana e também a melhoria da condição social deste.

Dentro deste cenário, foram fornecidos subsídios suficientes para que se pudesse obter uma conclusão a respeito da atividade desenvolvida no modelo "UBER" se considerada um trabalho precário ou não e quais os seus impactos quanto a dignidade do trabalhador e em seus direitos da personalidade.

\section{AS NOVAS FORMAS DE RELAÇÃO DE TRABALHO}

As relações de trabalho ao longo do tempo experimentaram enormes transformações, a exemplo da necessidade de criação de cargos relativos a atividades mais complexas em virtude dos avanços das técnicas de produção, a flexibilização das jornadas de trabalho e da hierarquia das chefias, até atingir o ponto do movimento de terceirização das atividades menos nobres da empresa (BOLTANSKI e CHIAPELLO, 2009). 


\section{Personalidade Acadêmica Homenageada:}

\section{Carlos Aurélio Mota de Souza (Universidade Ibirapuera - UNIB)}

Cada vez mais com o avanço da tecnologia o mundo tem experimentado transformações em vários setores, principalmente quanto às formas como novos serviços são criados e prestados.

Com o desenvolvimento de novas formas de exploração de atividades econômicas, as relações trabalhistas têm sido modificadas. As estruturas clássicas passam a dar lugar a uma nova organização.

Atualmente, muitas empresas não possuem mais estruturas físicas no local onde desenvolvem suas atividades, tampouco possuem empregados, existindo na verdade uma nova espécie de colaboradores, porém sem vínculo, sem subordinação direta, sem jornada de trabalho pré-definida.

Já no final do século XX a tecnologia redesenhava o cenário das relações de trabalho. Neste contexto podemos citar a evolução dos serviços bancários fora das agências, inicialmente por intermédio de caixas eletrônicos e posteriormente pelo uso dos computadores com acesso à internet, atingindo o nível de que atualmente, quase todas as operações bancárias podem ser realizadas por um smartphone.

Com toda essa transformação, com a inserção cada vez maior de meios eletrônicos e automatizados, os trabalhadores deste setor começaram a perder espaço, e consequentemente os seus empregos. Os poucos que se mantiveram nesta atividade experimentaram, ao longo dos anos, uma maior exigência do cumprimento de metas e menos obtenções de vantagens.

No início do século XXI a tendência se mantêm, o ambiente virtual (internet) trouxe novas possibilidades para a exploração da atividade econômica, principalmente os serviços fornecidos e prestados por aplicativos, em que o consumidor não precisa sair de casa ou ter contato com qualquer pessoa para efetivar uma compra por exemplo, pois todas as fases desta relação ocorrem pelo sistema, desde a escolha do produto até a forma de pagamento com a opção pelo modo de entrega.

HILL (2015) quando analisa a classe trabalhadora dos Estados Unidos com o desenvolvimento da economia on-demand, constata que as suas necessidades estariam sendo supridas dirigindo carros (Uber), alugando quartos e propriedades (Airbnb) e contratando por mensagens (TaskRabbit) para outras pessoas. 


\section{Personalidade Acadêmica Homenageada:}

\section{Carlos Aurélio Mota de Souza (Universidade Ibirapuera - UNIB)}

Por esta facilidade, celeridade e redução dos processos burocráticos é compreensível que este tipo de atividade ganhe espaço no mercado, porém, todas as benesses podem ser acompanhadas de algumas consequências, principalmente quanto às relações de trabalho.

Para verificar as consequências deste novo modelo de relação de trabalho será analisada a atividade desenvolvida pela empresa UBER, uma vez que sua atuação se tornou emblemática no Brasil.

\subsection{O MODELO “UBER" DE ATIVIDADE}

O modelo de atividade desenvolvido pela empresa UBER consiste na utilização de sua plataforma de tecnologia que conecta motoristas parceiros com os usuários por meio de um aplicativo para smartphones.

No próprio aplicativo há a possibilidade de registrar um cartão de crédito no qual as cobranças pelos serviços prestados serão efetuadas, no caso de pagamento que não em dinheiro. $O$ valor arrecadado pela empresa é dividido entre ela e o motorista.

Nesta relação, a empresa oferece a sua plataforma para que os interessados possam se cadastrar, de modo que os serviços sejam ofertados aos usuários possam ser prestados.

O inovador desta modalidade de atividade é a desnecessidade de contratação de empregados e da aquisição de veículos, uma vez que é responsabilidade do motorista parceiro possuir um automóvel dentro das exigências mínimas estabelecidas para que seja aceito na plataforma.

Apesar deste modelo de negócio ser extremamente lucrativo para a empresa em virtude dos baixos custos de seu desenvolvimento, uma vez que não possui folha de pagamento relativa a quem presta efetivamente o serviço, que não é responsável pela aquisição, manutenção e abastecimento dos veículos, deve-se atentar para a situação das condições dos indivíduos que na prática desenvolvem a atividade de transporte. 


\section{Personalidade Acadêmica Homenageada:}

\section{Carlos Aurélio Mota de Souza (Universidade Ibirapuera - UNIB)}

Os motoristas que se valem da plataforma da UBER, apesar de a empresa denomina-los parceiros, na verdade são prestadores de serviços, não possuindo os direitos assegurados aos trabalhadores empregados, como décimo terceiro salário, férias, adicional noturno e etc.

Pode-se dizer que esta nova forma de organização da atividade substitui o contrato de trabalho por um contrato comercial, de modo que o direito laboral não toca ou não deveria tocar esta nova relação, impedindo assim que vários dispositivos da legislação trabalhista a alcance (BOLTANSKI, CHIAPELLO, p. 270).

Se por um lado há a criação de mais uma possibilidade de atividade remunerada para aquele que não está inserido no mercado de trabalho, ou se está, busca complementação da renda, por outro há a existência de um novo posto de trabalho precarizado.

Esta forma de trabalho cresceu com as transformações ocorridas dentro das estruturas empresariais, a terceirização, também denominada de outsourcing, é uma das formas como a empresa encontrou para se eximir de muitas responsabilidades, como por exemplo as relativas aos acidentes de trabalho e às doenças profissionais (BOLTANSKI, CHIAPELLO, p. 270).

Logo, pode-se dizer que o modelo "UBER" é uma nova forma de outsourcing, pois não existe relação entre duas empresas como marcadamente ocorre na terceirização clássica, em que a empresa prestadora fornece os trabalhadores para desenvolver determinada atividade para a empresa tomadora, sob a conta e risco daquela, sendo que em regra, quando houver, a responsabilidade da tomadora será subsidiária.

Nesta nova relação, a empresa se vale de sua tecnologia para angariar trabalhadores que prestarão os serviços aos usuários do seu próprio aplicativo.

$\mathrm{Na}$ essência, o prestador do serviço deveria ser a própria empresa desenvolvedora do aplicativo, isso porque a sua remuneração decorrerá do serviço prestado e não da mera disposição (aderência) dos motoristas à estrutura tecnológica.

Apesar disso, quando se analisa a relação empresa-motorista, também é possível considerar que o aplicativo é apenas o instrumento (ferramenta) que conecta o usuário ao prestador de serviço disponível, ou seja, é uma comodidade/facilidade 


\section{Personalidade Acadêmica Homenageada:}

\section{Carlos Aurélio Mota de Souza (Universidade Ibirapuera - UNIB)}

de contato oferecida ao usuário e ao motorista, atua-se como um intermediário que encontra quem precisa do serviço e conecta àquele que está disponível a prestá-lo, em contrapartida a empresa recebe uma comissão por esta comodidade.

A complexidade desta relação é tamanha, que a própria justiça do trabalho diverge sobre qual seria a natureza do modelo "UBER", se corresponde a uma relação de emprego logo, os motoristas possuiriam os típicos direitos da legislação laboral, ou se corresponde a uma prestação de serviço, marcada notadamente por uma relação comercial.

\section{DAS CONSIDERAÇÕES TRABALHISTAS SOBRE O TEMA}

Conforme destacado no item anterior, a tecnologia veio a modificar e inovar as relações humanas, impactando de forma direta na maneira com que nos relacionamos com os demais e os efeitos disso nas mais variadas áreas da vida social.

Assim, é imprescindível abordar a questão sob o viés da legislação trabalhista, especificamente quanto aos requisitos caracterização da relação de emprego, posto ter o referido instituto intima ligação com o tema discutido no presente estudo.

Desta maneira, o capítulo abordará a visão e as considerações da questão na seara trabalhista sobre o tema, tendo em vista a sua necessidade e atualidade, conforme já descrito no capítulo anterior.

\subsection{DA RELAÇÃO DE EMPREGO E REQUISITOS CARACTERIZADORES}

Inicialmente é preciso fixar o fato de que conceito de trabalho e de emprego são diversos, restando claro que existem atividades que se enquadram no primeiro tipo e não no segundo, cabendo destacar que "a relação de trabalho é gênero do qual relação de emprego é espécie" para, ao fim possibilitar "concluir que se trata do uso do esforço humano buscando um resultado" (GODINHO, 2013, p. 277-278).

Situação diversa é a relação de emprego que, para sua verificação e/ou constatação, necessita da presença de alguns requisitos, os quais estão insculpidos, 


\section{Personalidade Acadêmica Homenageada:}

\section{Carlos Aurélio Mota de Souza (Universidade Ibirapuera - UNIB)}

basicamente, no artigo $3^{\circ}$ da Consolidação das Leis do Trabalho ${ }^{1}$, sendo necessário a investigação da presença de tais elementos mediante a análise dos fatos para se chegar a conclusão da existência de uma relação de trabalho ou de emprego.

Necessário, ainda, que todos os elementos exigidos pela legislação estejam presentes, sendo que a falta de um deles desnatura a relação de emprego podendo, de outro modo, caracterizar outros tipos de relação, importando na diversidade de efeitos que cada uma produzirá.

Assim, com base no citado artigo da legislação consolidada, para se ter uma relação de emprego é necessário que estejam presentes: o trabalho prestado por uma pessoa física, a pessoalidade na prestação de tais serviços, a não eventualidade dos serviços prestados, a onerosidade de tais serviços, a subordinação e, por último e de forma não unânime pela doutrina, a alteridade.

Acerca da não eventualidade, importa destacar que sua definição é controvertida, posto que exige a compreensão do conceito de continuidade, ou seja, a sucessão de obrigações e direitos que surgem com o desenvolvimento da relação trabalhista durante o tempo.

Nesse particular, três teorias tentam explicar tal elemento, a qual se dá por meio de exclusão, ou seja, sendo enquadrado em tais teorias, o trabalho seria eventual: descontinuidade (o trabalho prestado sem a continuidade seria considerado como eventual), evento (o trabalho prestado por eventos seria considerado como eventual), fins do empreendimento (será considerado trabalho não eventual, para fins da referida teoria, àquele prestado diretamente quanto aos fins do empreendimento) e a da fixação jurídica (será trabalhador eventual àquele que não se fixe a uma fonte de trabalho específico).

Sobre tais teorias, a doutrina e a jurisprudência consideram a teoria dos fins do empreendimento como elemento balizador para diferenciar os serviços prestados como eventual ou se enquadrados como trabalho não eventual.

Entretanto, como dito, somente o requisito da não eventualidade não é suficiente para analisar se a relação é de emprego ou não. Para tanto, necessário

\footnotetext{
${ }^{1}$ Art. $3^{\circ}$ - Considera-se empregado toda pessoa física que prestar serviços de natureza não eventual a empregador, sob a dependência deste e mediante salário.
} 


\section{Personalidade Acadêmica Homenageada:}

\section{Carlos Aurélio Mota de Souza (Universidade Ibirapuera - UNIB)}

verificar o elemento onerosidade, o qual é caracterizado pelo termo "mediante salário" descrito pela legislação, o qual pode ser compreendido no fato do empregado colocar sua força de trabalho ao empregador mediante uma contraprestação.

Ocorre, entretanto, que a simples paga não é suficiente para verificação de tal requisito, devendo a pesquisa ser feita sob aspectos objetivos e subjetivos (DELGADO, 2013, P. 289). Para o autor, o primeiro aspecto se dá em razão do ato do empregador em remunerar o empregado devido a existência de um contrato de trabalho, podendo ser esta contraprestação ocorrer de forma diária, semanal, quinzenal ou mensal. No âmbito subjetivo, a pesquisa tem como objetivo verificar a intenção econômica da relação, ou seja, afasta-se o trabalho voluntário, por exemplo, que não tem tal escopo.

Quanto ao terceiro requisito - pessoalidade - se dá sob o viés do empregado, ou seja, do sujeito da relação trabalhista e que não pode ser substituído por terceiro na prestação de serviços (salvo exceções pontuais permitidas na legislação), devendo ser necessariamente prestado por pessoa física.

Em relação a figura do empregador, necessário destacar o fato que a análise de tal elemento é mitigada, posto que se admite a sucessão de empregadores.

No que tange ao elemento "subordinação" pode ser entendida como "uma situação jurídica derivada do contrato de trabalho, na qual o empregador dirige a realização dos serviços e o empregado acolhe esta direção, incorporando-a no modo em que realiza o serviço" (DELGADO, 2013, p. 292), ou seja, resume-se ao fato de que será subordinado àquele que se submete a direção e controle na realização das atividades.

Ocorre, entretanto, que o tema ainda é controvertido, seja em razão da existência de dependência ou em função de sua natureza jurídica. Assim, há as seguintes teorias que tentam explicar tais elementos.

Acerca da natureza jurídica, a definição mais adotada pelos doutrinadores é a de que subordinação é "um fenômeno jurídico, derivado do contrato estabelecido entre trabalhador e tomador de serviços, pelo qual o primeiro acolhe o direcionamento objetivo do segundo sobre a forma de efetuação da prestação do trabalho." (DELGADO, 2013, p.294) 


\section{Personalidade Acadêmica Homenageada:}

\section{Carlos Aurélio Mota de Souza (Universidade Ibirapuera - UNIB)}

Entretanto, há outros que afirmam se tratar de outras naturezas diversas da jurídica, tal como a social, técnica, econômica e a hierárquica.

Sobre a questão das dimensões jurídicas da subordinação, é possível adotar alguns critérios: clássico, estrutural, objetivo e a subordinada. A primeira pode ser definida como a situação jurídica que deriva do contrato de trabalho, onde o empregado se submete ao poder de direção do empregador quando da prestação de seus serviços. Já o quesito estrutural, se resume ao fato do empregado participar da dinâmica do empregador, sendo irrelevante ordens diretas ou não. Em relação a dimensão objetiva, é àquela em que os serviços prestados pelo empregado se integram às finalidades do empreendimento. E, por fim, a subjetiva, é àquela direcionada ao poder de comando do empregador.

E, por fim, conforme destacado no início, verifica-se a presença da alteridade, a qual não é considerada por alguns doutrinadores como elemento essencial para caracterizar a relação de emprego.

Tal critério é dirigido exclusivamente ao empregador, funcionando como um elemento de exclusão da relação de emprego, ou seja, só será empregador àquele que obtêm lucros de uma atividade e que também assume os riscos desta. Assim é que, se a atividade encerrar resultados positivos ou negativos, ao contrato de trabalho não ocorrerá qualquer tipo de mudança, não podendo o empregador imputar tais riscos ao empregado.

Desta maneira, conforme já dito, a presença de tais elementos torna viável o reconhecimento da relação de emprego. Ao contrário, estando ausente qualquer um desses elementos, desnatura-se a relação de emprego, dando a sorte de configurar qualquer outro tipo de relação, seja de trabalho autônomo, seja de trabalho eventual ou até mesmo de relação de trabalho.

Assim, a referida questão em relação ao motorista de aplicativo, por se tratar de relação jurídica nova, guarda tormentosa e detalhada análise, a qual merece uma detida verificação quanto a seus elementos ensejadores, resultando no exercício de longa incursão nos elementos fáticos que a delineiam, a qual será brevemente descrita no tópico a seguir. 


\section{Personalidade Acadêmica Homenageada:}

\section{Carlos Aurélio Mota de Souza (Universidade Ibirapuera - UNIB)}

\subsection{A PRESTAÇÃO DE SERVIÇOS DO MOTORISTA INSCRITO NO APLICATIVO UBER E A SUA ANÁLISE PERANTE A JUSTIÇA DE TRABALHO}

Conforme descrito no capítulo anterior, a verificação do cotidiano na prestação de serviços é primordial e imprescindível para se chegar a conclusão da existência ou não - de uma relação de emprego, mediante a investigação acerca da presença dos elementos que caracterizam a citada relação.

Acerca do tema, ganha destaque o fato de ser inovação a utilização de aplicativos e da informática na atividade de prestador de serviços, posto que, quando da definição dos elementos (1942) não se verificam a existência de tais meios de solicitação dos serviços.

Primeiramente, é importante destacar que para ser motorista do aplicativo é necessário um cadastro prévio do interessado, que será submetido a análise, inclusive comportamental e psicológica, bem como ter a sua situação em ordem perante autoridades de trânsito e de outros órgãos públicos que fazem tal controle.

Ainda, impende destacar o fato de que o candidato necessita ser proprietário de veículo para realização de corridas, bem como se sujeitar a corridas e determinações constantes do citado aplicado, dos quais angaria corridas e the desconta um percentual por cada uma delas.

Não obstante a tal fato, importa ressaltar que esse motorista também se submete a avaliações dos clientes do aplicativo, podendo ser, inclusive, excluído de seus cadastros pela ferramenta eletrônica caso suas avaliações não sejam satisfatórias.

Feitas tais considerações, se verifica a dificuldade da tarefa de proceder a verificação acerca dos elementos caracterizadores do vínculo de emprego, posto se tratar de prestação de serviços que inova no modelo clássico definido.

Nesse particular, a Justiça do Trabalho se divide quanto as consequências laborais do modelo "UBER", tendo em vista a existência de decisões que entendem não haver vínculo empregatício entre o motorista e a empresa, uma vez que não conseguiria ser cumprido um dos requisitos para tal configuração: a subordinação. 


\section{Personalidade Acadêmica Homenageada:}

Carlos Aurélio Mota de Souza (Universidade Ibirapuera - UNIB)

Exemplo é a decisão proferida no RO 1001574-25.2016.5.02.0026 pelo TRT $2^{\text {a }}$ Região ( $8^{\text {a }}$ Turma), em que se considerou que em virtude de o motorista possuir a liberdade de cumprir a sua própria rotina de trabalho, sem sofrer qualquer tipo de fiscalização, sendo permitido deixar de trabalhar a qualquer tempo, não estaria configurada a existência de poder diretivo por parte da empresa, ou seja, da existência de subordinação.

Por outro lado, há a possibilidade de se vislumbrar a existência de vínculo empregatício com base no mesmo requisito que na decisão anterior considerou-se inexistente, ou seja, a subordinação.

Para o mesmo TRT (2 $2^{\mathrm{a}}$ Região $-15^{\mathrm{a}}$ Turma), ao julgar o RO 100012389.2017.5.02.0038 verificou-se que em relação à forma como a empresa trabalha (aplicativo de celular), há controle da concretização de serviço prestado pelo motorista, não se tratando o uso da ferramenta de uma simples parceria entre o motorista e a empresa.

Esta conclusão decorreu do fato de que se fosse uma ferramenta eletrônica, por certo a empresa não sugeriria o preço do serviço de transporte a ser prestado e o percentual a ela destinado e também não condicionariam a permanência do motorista às avaliações feitas pelos usuários do serviço, de modo que a plataforma estivesse a disposição de qualquer interessado, sem qualquer interferência no resultado, estipulando um valor fixo a ser pago pelo motorista pelo tempo de utilização.

Também, a decisão foi escorada na própria "reforma trabalhista" que promoveu alteração no art. $6^{\circ}$ da CLT prevendo que os meios informatizados de comando, controle e supervisão se equiparam, para fins de subordinação jurídica, aos meios pessoais e diretos de comando, controle e supervisão do trabalho alheio.

A divergência de posicionamento nos órgãos da Justiça do Trabalho se deve em grande parte a forma como se analisa a situação, se a plataforma da UBER for considerada apenas uma ferramenta de conexão entre o motorista e o usuário não será verificada a existência de subordinação, uma vez que o motorista poderá aceitar ou recusar o serviço, além de decidir as horas que irá trabalhar, os seus intervalos e que a recusa não lhe acarretara penalidade alguma. Por outro lado, se entender que a atividade prestada pela UBER é essencialmente de transporte, que sua 


\section{Personalidade Acadêmica Homenageada:}

\section{Carlos Aurélio Mota de Souza (Universidade Ibirapuera - UNIB)}

remuneração é decorrente deste serviço e que o motorista é submetido a avaliações e controle de valores a serem cobrados além de que deve atender às exigências mínimas da empresa para poder valer-se de sua plataforma, o resultado será pelo reconhecimento de subordinação e consequentemente do vínculo empregatício.

As decisões citadas podem ilustrar todas as demais proferidas em situações envolvendo o modelo "UBER" de atividade, uma vez que o reconhecimento ou não do vínculo empregatício tem como base a interpretação sobre a existência da subordinação jurídica na relação.

A questão envolvendo o modelo "UBER" de atividade é recente, e demanda enorme complexidade quanto ao seu enquadramento, se o vínculo com o motorista configura ou não uma relação de emprego, de modo que ainda não há uma definição da Justiça do Trabalho, fato que gera insegurança jurídica tanto para a empresa como para o trabalhador que a ela se vincula.

\section{OS DIREITOS DA PERSONALIDADE DO TRABALHADOR E A AGENDA DO TRABALHO DECENTE}

Por se tratar de uma inovação, muito se tem discutido acerca da natureza jurídica da prestação de serviços e a se a forma com que se dá tal relação de trabalho acaba por alijar ou excluir o motorista inscrito em tais aplicativos de seus direitos decorrentes da dignidade da pessoa, além de se analisar se o trabalho prestado é um trabalho decente, conforme definição apresentada pela Organização Internacional do Trabalho.

Tais questionamentos são importantes na medida em que se discute se as condições impostas ao trabalhador caracterizam precariedade das relações de trabalho e se, em relação a isso, esta o trabalho prestado como não incluso na agenda do trabalho decente que, por sua vez, também tem forte ligação com os direitos da personalidade do trabalhador.

\subsection{O PRINCÍPIO DA DIGNIDADE DA PESSOA}




\section{Personalidade Acadêmica Homenageada:}

Carlos Aurélio Mota de Souza (Universidade Ibirapuera - UNIB)

Entre os fundamentos da República Federativa do Brasil encontra-se o princípio da dignidade da pessoa humana (art. 1ํㅡ. III) que possui estrita relação com a qualidade inerente de cada ser humano de ser respeitado seja pelo Estado seja por outro indivíduo, também é compreendido por um complexo de direitos e deveres fundamentais que objetivam assegurar condições mínimas necessárias para uma vida saudável (SARLET, 2001, p. 60). Também "o princípio da dignidade humana é tido como princípio fundamental em uma sociedade livre e democrática" (BERTONCINI, MARKOVICZ, 2012, p. 382).

Pode-se dizer que as condições mínimas necessárias para uma vida saudável fazem parte do chamando mínimo existencial, nele estão compreendidas todas as necessidades básicas do ser humano para que sua existência seja digna, como alimentação, moradia, saúde, educação, trabalho e etc.

Nesse sentido

[...] as prestações materiais que asseguram condições mínimas de sobrevivência estão positivadas, no direito brasileiro, sob o título de "Direitos Sociais", no Capítulo II (artigos $6^{\circ}$ a 11) do Título II ("Dos direitos e garantias fundamentais") da Constituição da República Brasileira de 1988, abrangendo o direito à educação, saúde, trabalho, moradia, lazer, segurança, previdência social, proteção à maternidade e à infância, assistência aos desamparados, dentre outros. (MATSUDA, PEREIRA, SOUZA, p 15)

Verifica-se que o mínimo existencial implica na observância à garantia ao direito ao trabalho, que como direito social faz parte do subsistema dos direitos fundamentais, de modo que reconhecendo a existência de um segmento social economicamente vulnerável, busca através da regulamentação/normatização de relações econômicas e de direitos prestacionais atribuir a todos os benefícios da vida em sociedade (NUNES JUNIOR, 2009, p. 70).

Assim, conjugados o mínimo existencial e a dignidade da pessoa humana tem-se um paradigma para que "sejam visualizados os direitos assegurados a todos os cidadãos", principalmente aqueles inseridos nas camadas sociais menos favorecidas "que sofrem de forma mais gravosa devido a sua condição de inferioridade na competição existente na sociedade" (FERNANDES, 2017, p. 316). 


\section{Personalidade Acadêmica Homenageada:}

\section{Carlos Aurélio Mota de Souza (Universidade Ibirapuera - UNIB)}

Justamente pela existência de grupos menos favorecido é que o princípio da dignidade humana deve pautar todas as relações da vida em sociedade, e não somente na perspectiva Estado-cidadão.

Diante disso, o direito ao trabalho sempre deverá observar condições mínimas para que a dignidade daquele que o exerce seja respeitada, porém, em que pese tal necessidade, a tendência atual é contrária, uma vez que o surgimento cada vez maior de trabalhos precários e a flexibilização da proteção dada ao trabalhador pelo Estado conduzem à uma ideia de licitude e até mesmo de estimulo do exercício de atividades cada vez menos dignas a uma vida saudável, seja pelo modo como são exercidas, seja pela forma como são remuneradas.

Desta forma, trabalhos que não garantam ou que sejam relativizados a quem exerce direitos básicos como férias, repouso semanal remunerado, intervalo entre jornadas e etc somente conduzem à violação da dignidade do trabalhador, de modo que atingirão diretamente direitos da sua personalidade como a saúde e a integridade física consubstanciadas no bem estar do indivíduo, não permitindo o gozo de uma vida saudável.

Nesse sentido, o modelo UBER de atividade pode, para aqueles que entendem não estar configurado a existência de vínculo empregatício entre a empresa e o motorista, ser considerado como um exemplo de criação de trabalho precário, isso porque retira do trabalhador direitos básicos como salário mínimo, férias, descanso semanal remunerado dentre outros, o que afeta de maneira direta a sua dignidade, uma vez que a ele não será garantido o mínimo existencial.

Justamente por conta desta situação que as novas relações de trabalho merecem um estudo aprofundado, para que se evite a proliferação de atividades e trabalhos que não sejam capazes de respeitar a dignidade de quem os exerce nem fornecer o mínimo existencial para uma vida digna, afetando diretamente direitos da personalidade como a saúde e o bem estar.

No tópico seguinte será realizada uma correlação entre as novas relações de trabalho e a agenda do trabalho decente. 


\section{Personalidade Acadêmica Homenageada:}

Carlos Aurélio Mota de Souza (Universidade Ibirapuera - UNIB)

\subsection{AS NOVAS RELAÇÕES DE TRABALHO E A AGENDA DO TRABALHO DECENTE}

A Organização Internacional do Trabalho, principal organismo internacional ligado a área do trabalho, procura disseminar o fato de que o trabalho não pode ser considerado como mercadoria, visando, com isso, dar um norte aos países integrantes e também traçar regras gerais para que não se precarize a mão-de-obra pelo mundo e que se adotem condições mínimas para prestação do trabalho, tudo com a finalidade de se preservar a dignidade do ser humano.

Para tanto - e atenta a inserção da tecnologia na realidade de cada país e em seus mercados de trabalho - o referido Organismo definiu, em 1998, o conceito de trabalho decente, o qual se deu mediante a estipulação de objetivos e aplicação das convenções e recomendações, além da constante verificação de seu cumprimento, visando a concretização de tal entendimento, afastando com isso a instalação da precarização na prestação de serviços.

O trabalho decente é definido pela Organização Internacional do Trabalho como sendo:

[...] o ponto de convergência dos quatro objetivos estratégicos da OIT: o respeito aos direitos no trabalho (em especial aqueles definidos como fundamentais pela Declaração Relativa aos Direitos e Princípios Fundamentais no Trabalho e seu seguimento adotada em 1998: (i) liberdade sindical e reconhecimento efetivo do direito de negociação coletiva; (ii) eliminação de todas as formas de trabalho forçado; (iii) abolição efetiva do trabalho infantil; (iv) eliminação de todas as formas de discriminação em matéria de emprego e ocupação), a promoção do emprego produtivo e de qualidade, a extensão da proteção social e o fortalecimento do diálogo social.

Desta maneira, segundo Brito Filho (2004, p. 61) pode ser considerado como:

[...] um conjunto mínimo de direitos do trabalhador que corresponde: à existência de trabalho; à liberdade de trabalho; à igualdade no trabalho; ao trabalho com condições justas, incluindo a remuneração, e que preservem sua saúde e segurança; à proibição do trabalho infantil; à liberdade sindical; e à proteção contra os riscos sociais. 


\title{
Personalidade Acadêmica Homenageada:
}

Carlos Aurélio Mota de Souza (Universidade Ibirapuera - UNIB)

Desta forma, entende-se como trabalho decente um elemento capaz de concretizar o princípio da dignidade da pessoa humana, conforme descrito no inciso III do artigo $1^{\circ}$ da Constituição da República e também atender ou garantir um patamar mínimo civilizatório em tal ambiente, posto que o direito do trabalho conserva, como um de seus objetivos, uma função de civilidade, além de se garantir o atendimento ao princípio da vedação ao retrocesso, além de buscar evitar a precarização da relação entre capital e trabalho.

Assim é que, com isso, o cumprimento a tais regulamentos e tratados editados pela Organização Internacional do Trabalho, tem como finalidade buscar a igualdade e o estabelecimento de um patamar mínimo civilizatório, tornando irregular a precarização da mão-de-obra.

Importa ressaltar o fato de que sem as condições mínimas de prestação de trabalho decente, o trabalhador estará inserido em uma relação de precarização, o que só torna mais grave a situação de retrocesso social e, por conseguinte, a referida prestação de serviços não atende a fundamentos da Constituição da República, tais como a dignidade da pessoa humana e também a melhoria da condição social deste.

Acerca do assunto, importante a transcrição das considerações de Souto Maior:

\begin{abstract}
Se um trabalhador trabalha em condição insalubre, por exemplo, ruído, a obrigação do empregador de pagar o respectivo adicional de insalubridade não se elimina pelo fato de já ter este mesmo empregador pago ao empregado adicional de periculosidade pelo risco de vida a que o impôs. Da mesma forma, o pagamento pelo dano à saúde, por exemplo, perda auditiva, nada tem a ver com o dano provocado, por exemplo, pela radiação. Em suma, para cada elemento insalubre é devido um adicional, que, por óbvio, acumulase com o adicional de periculosidade, eventualmente devido. Assim, dispõe, aliás, a Convenção № 155, da OIT, ratificada pelo Brasil.
\end{abstract}

Desta feita, abordando a questão da prestação de serviços pelo motorista aos aplicativos de tecnologia, deve-se considerar o fato de que a prestação de tais serviços não seja apenas considerada como "mercadoria", mas que o trabalhador o faça com direitos mínimos assegurados para que se possa garantir, além de seu sustento, um mínimo de dignidade e de melhoria de sua condição social. 


\section{Personalidade Acadêmica Homenageada:}

\section{Carlos Aurélio Mota de Souza (Universidade Ibirapuera - UNIB)}

Pelo exposto, tão importante como a existência das vagas de trabalho ou da prestação em si é o cumprimento da agenda do trabalho decente no atendimento e respeito aos princípios, explícitos e implícitos, da Constituição da República, visando, com isso, implantar condições mínimas de respeito às relações de trabalho, com intuito de evitar o retrocesso social, garantir a dignidade da pessoa humana e evitar a precarização na prestação de tais serviços.

\section{CONCLUSÃO}

Conforme o mundo experimenta a evolução da tecnologia novas formas de relações são criadas, dentre elas as relativas ao trabalho, na qual o modelo UBER de atividade demonstra ser inovadora e pioneira quando considerada a sua repercussão e a sua abrangência.

Porém, nestas novas relações de trabalho, principalmente oportunizadas pelo desenvolvimento tecnológico, observa-se que as atividades exercidas pelos trabalhadores têm perdido valor, uma vez que são tratados cada vez mais como prestadores de serviços regulamentados por contratos comerciais do que trabalhadores com uma relação regida por contratos de trabalho e consequentemente, pela proteção que a legislação laboral é capaz de conferir.

Um dos impactos desta nova modalidade de relação de trabalho diz respeito à dignidade do trabalhador, isso porque, a ausência do reconhecimento de direitos trabalhistas como salário mínimo, férias, descanso semanal remunerado, $13^{\circ}$ salário, dentre outros, acarretam na impossibilidade de o trabalhador poder melhorar de vida, possibilitando inclusive o contrário, a sua degradação.

Nesse sentido, a perspectiva da inexistência de vínculo empregatício entre a empresa UBER e o motorista acarreta nas seguintes situações: o trabalhador não possui ao final do mês de trabalho a garantia de um salário mínimo fixo, o que impede 


\section{Personalidade Acadêmica Homenageada:}

Carlos Aurélio Mota de Souza (Universidade Ibirapuera - UNIB)

de realizar planos futuros, uma vez que seu eventual ganho é incerto; não possui jornada de trabalho definida, o que implicará na necessidade de executar o trabalho com vistas a garantir o mínimo necessário para a sua subsistência, isto pode ocorrer em $4,6,8,10$ ou 12 horas, de modo que a excedente a $8^{\text {a }}$ hora não será remunerada pela empresa como extra; também não haverá intervalo intrajornada nem entre as jornadas, tampouco descanso semanal remunerado, fatos que poderão ocasionar impactos na saúde do trabalhador, uma vez que se não alcançar os valores necessários a arcar com suas necessidades básicas se verá obrigado a trabalhar todos os dias e com intervalos exíguos entre as jornadas; nesse tipo de relação o trabalhador também nunca terá férias garantidas, tampouco remuneradas, o que leva a crer que caso não consiga durante o ano constituir uma boa reserva, certamente não terá lazer, tampouco se afastará das atividades.

Nota-se que nestas situações não haverá como o trabalhador possuir uma vida digna, uma vez que trabalhará sem perspectiva alguma de melhoria na sua condição social, a atividade executada no modelo descrito somente conduzirá a ausência de respeito à dignidade do indivíduo que a realiza, uma vez que não se garantirá o mínimo existencial na vertente do direito ao trabalho, pois a relação será marcada pela ausência de salário mínimo, de férias, de descanso semanal remunerado, de horas extras e etc, que afetarão os direitos da personalidade no tocante a saúde e ao bem estar.

O trabalho executado será confundido como mercadoria, de modo a não ser valorizado conforme deveria, nos termos pretendidos pela Constituição da República, pois sem as condições mínimas de prestação de trabalho decente, o trabalhador estará inserido em uma relação de precarização, o que só torna mais grave a situação de retrocesso social e, não atendendo a fundamentos da República, tais como a dignidade da pessoa humana e também a melhoria da condição social (consubstanciada na valorização do trabalho).

Estes são apenas alguns reflexos que podem decorrer do trabalho prestado no modelo UBER de atividade. 


\section{Personalidade Acadêmica Homenageada:}

Carlos Aurélio Mota de Souza (Universidade Ibirapuera - UNIB)

Ademais, com relação a agenda do trabalho decente, conclui-se que o trabalho em análise deve ser considerado como precário, em especial por não respeitar um padrão mínimo de direitos ao indivíduo que o exerce.

Diante das várias consequências negativas, principalmente sociais, é importante que a jurisprudência pacifique a questão quanto a existência ou não de vínculo empregatício entre o a empresa e os motoristas, para isso os julgadores não se devem pautar apenas por aspectos econômicos, mas sim pela interpretação da lei com vistas a atender os princípios constitucionais da valorização do trabalho e da dignidade da pessoa humana com a proteção dos direitos da personalidade no tocante a saúde e o bem estar do indivíduo.

\section{REFERÊNCIAS}

BERTONCINI, Mateus Eduardo Siqueira. MARKOVICZ, Silvia. O princípio da dignidade da pessoa humana e a responsabilidade social das empresas privadas. Revista Jurídica - UNICURITIBA, Curitiba, v. 2, oㅜ 29, 2012. Disponível em < http://revista.unicuritiba.edu.br/index.php/RevJur/article/view/529/413> Acesso em 05.set.2018.

BOLTANSKI, Luc e CHIAPELLO, Ève. O novo espírito do capitalismo. São Paulo, Martins Fontes, 2009.

BRITO FILHO, José Cláudio Monteiro. Trabalho Decente: análise jurídica da exploração, trabalho forçado e outras formas de trabalho indigno. São Paulo: LTr, 2004.

DELGADO, Maurício Godinho. Curso de Direito do Trabalho. 12. ed. São Paulo: Ltr, 2013.

FERNANDES, David Augusto. Anodo de sacrifício: a pobreza e a indignidade da pessoa humana. Revista Jurídica - UNICURITIBA, Curitiba, v. 3, oㅡ 48, 2017. Disponível em http://revista.unicuritiba.edu.br/index.php/RevJur/article/view/2182/1362> Acesso em 05.set.2018.

HILL, Steven. Raw Deal: how the "uber economy" and runaway capitalism are screwing american workers. New York: St. Martin's Press, 2015 
Personalidade Acadêmica Homenageada:

Carlos Aurélio Mota de Souza (Universidade Ibirapuera - UNIB)

MATSUDA, Juliana Tiemi Maruyama. PEREIRA, Helida Maria, SOUZA, Luciana Camila. $O$ mínimo existencial como limite à aplicação da reserva do possível aos direitos fundamentais sociais. Disponível em < https://www.google.com/url?sa=t\&rct=j\&q=\&esrc=s\&source=web\&cd=12\&ved=2ahU KEwjDk_6x26fdAhWMfZAKHZCiB7EQFjALegQIAhAC\&url=http\%3A\%2F\%2Fwww.a gu.gov.br\%2Fpage\%2Fdownload\%2Findex\%2Fid\%2F\%25207306306\&usg=AOvVa w347_fmmSnboLxUGrGYzjrh > Acesso em 06.set.2018.

NUNES JUNIOR, Vidal Serrano. A Cidadania Social na Constituição de 1988 Estratégias de Positivação e Exigibilidade Judicial dos Direitos Sociais. São Paulo: Verbatim, 2009.

TRIBUNAL REGIONAL DO TRABALHO DA 2a REGIÃO. Recurso Ordinário no 1001574-25.2016.5.02.0026. Relatora Juíza Sueli Tomé da Ponte, dj-e. 14.12.2017.

TRIBUNAL REGIONAL DO TRABALHO DA 2 $2^{\underline{a}}$ REGIÃO. Recurso Ordinário no 1000123-89.2017.5.02.0038. Relatora Juíza Beatriz de Lima Pereira, j. 24.08.2018.

Constituição Federal. $1988 . \quad$ Disponível em: http://www.planalto.gov.br/ccivil_03/constituicao/constituicaocompilado.htm. Acesso em 31 ago. 2018.

OIT. Disponível em: <http://www.ilo.org/brasilia/temas/trabalhodecente/WCMS_302660/lang--pt/index.htm>. Acesso em: 31 ago.2018.

SARLET, Ingo Wolfgang. A eficácia dos direitos fundamentais. $2^{\mathrm{a}}$ ed. Porto Alegre: Livraria do Advogado, 2001.

SOUTO MAIOR, Jorge Luiz. O Direito do Trabalho como Instrumento de Justiça Social. São Paulo: LTr, 2000. 